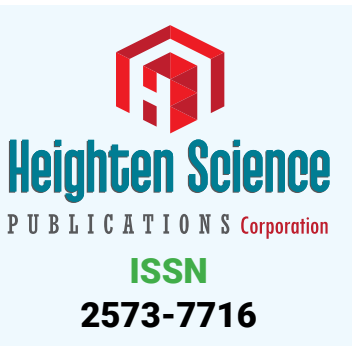

*Address for Correspondence: Dr. Pirabu Sakthivel, Department of Otorhinolaryngology and Head \& Neck surgery, All India Institute of Medical Sciences, New Delhi, India, Tel: 9958744547; Email: pirabusakthivel@gmail.com

Submitted: 03 June 2017

Approved: 14 June 2017

Published: 16 June 2017

Copyright: @ 2017 Sakthivel P, et al. This is an open access article distributed under the Creative Commons Attribution License, which permits unrestricted use, distribution, and reproduction in any medium, provided the original work is properly cited

Keywords: Mucoepidermoid carcinoma; Facialtics; Parotidectomy

\title{
Recurrent Mucoepidermoid Carcinoma of Parotid with Facial Tics - Report of an unusual case
}

\author{
Pirabu Sakthivel*, Chirom Amit Singh, Smriti Panda, Suresh \\ Chandra Sharma, Konki Malla Abhilash and Milind Sagar \\ Department of Otorhinolaryngology \& Head and Neck surgery, All India Institute of Medical \\ Sciences, India
}

\section{ABSTRACT}

We report an interesting case of a 21 year old male who presented with recurrent mucoepidermoid carcinoma of parotid with facial nerve involvement as facial tics. Intraoperatively, the tumour was noted to be firm, irregular and adherent to the underlying structures. The patient underwent extended total parotidectomy, division of buccal branch of facial nerve, selective neck dissection with cervical local rotational flap repair and post-operative radiotherapy. This presentation of Mucoepidermoid carcinoma with involvement of facial nerve as facial tics is one of the rare unique reported cases.

\section{INTRODUCTION}

Mucoepidermoid carcinoma (MEC) of the salivary glands is believed to arise from pluripotent reserve cells of the excretory ducts that are capable of differentiating into squamous, columnar, and mucous cells [1]. Although MEC accounts for less than $10 \%$ of all tumors of the salivary gland, it constitutes approximately $30 \%$ of all malignant tumors of the salivary gland [2]. MEC is the most common malignant tumour to arise in children and adolescents under 20 years of age [3]. Due to the cellular heterogeneity, the histologic composition, biological behaviour, and clinical course of MEC vary. The tumour usually presents as an asymptomatic firm to hard mass. Pain and facial paralysis are associated with high grade malignant tumors. They can recur, and they can metastasize to regional lymph nodes or distant viscera [2,3]. Because of the relative rarity of these tumors and the remarkable variability in their biological behaviour, opinions differ about the appropriate classification, grading, and treatment [4]. Although surgery generally is accepted as the primary treatment for MEC, the extent of parotidectomy, the indications for neck dissection and need for adjuvant therapy are not clear [2,4].

We report an unusual unique case of recurrent MEC of right parotid gland with facial tics who underwent extended total parotidectomy, division of buccal branch of facial nerve, selective neck dissection with cervical local rotational flap repair and post-operative radiotherapy.

\section{CASE REPORT}

A 21year-old male presented to our outpatient department with painless progressive swelling in right parotid region associated with facial tics for the past 1 year. There was history of excision of the swelling before 2 years at local hospital and the patient 
was advised it was benign in nature, although no records were retrievable from the patient. After surgery the patient was asymptomatic for six months but he started developing painless progressive swelling of right parotid along with facial tics. Clinical examination revealed a firm, discrete, oval swelling of size $5 \times 3 \mathrm{~cm}$ with skin puckering along with healed preauricular scar (Figure 1A). His facial nerve movements were intact but patient had facial tics (Video 1). No regional lymph nodes were palpable. MRI revealed an infiltrative mass lesion on the superficial lobe of the right parotid gland with both cystic and solid components (Figure 1B,1C). Fine needle aspiration cytology [FNAC] reported it to be a MEC. The patient was planned for surgery under general anaesthesia. Intraoperatively, the mass was irregular and firmly adherent to masseter and skin with buccal branch of facial nerve completely engulfed in the tumour with few intraparotid lymph nodes, raising the suspicion of high grade malignancy. Extended total parotidectomy along with sacrifice of buccal branch of facial nerve with selective neck dissection was performed using modified Blair's incision (Figure 2A). A local cervical rotational flap (Figure 2B,2C,2D) was done to cover the skin defect and the wound was closed in layers after placing a drain. Post operatively, wound was well healed and patient had temporary lower trunk facial paresis (Figure 2D,2E). Histopathological slides showed intermediate grade mucoepidermoid carcinoma [Brandwein grade II] with aggressive infiltrative boundaries (Figure 3) with no lymph nodes and skin involvement. In view of clinical aggressiveness and infiltrative boundaries [stage IVa disease] the patient was subjected to post-operative radiotherapy. The patient is doing fine in the six monthly follow up.

\section{DISCUSSION}

MEC is the most common salivary cancer affecting the parotid gland and comprising approximately $30 \%$ of malignant tumors [2]. It usually affects patients from third to fifth decade of life with slight female preponderance [4]. Ionising radiation, therapy with radioactive iodine, cellular phone usage have been considered as specific etiological factors for parotid malignancies [2].

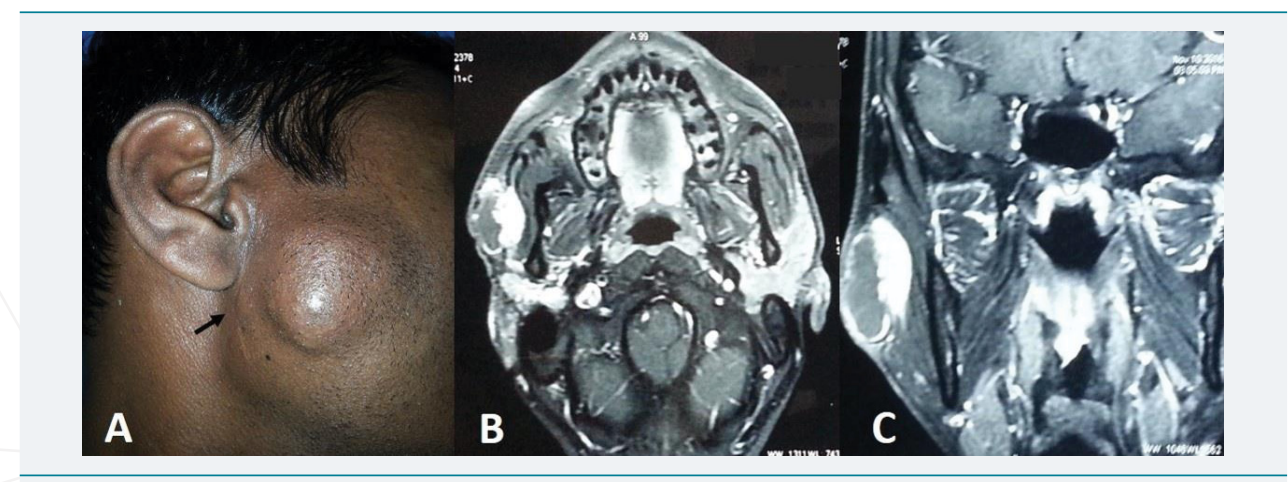

Figure 1: A Clinical picture showing preauricular swelling and scar of previous surgery (arrow). B\&C. Axial and coronal MRI post contrast T1 weighted images show peripheral enhancement of the cystic component and intense enhancement of the solid component.

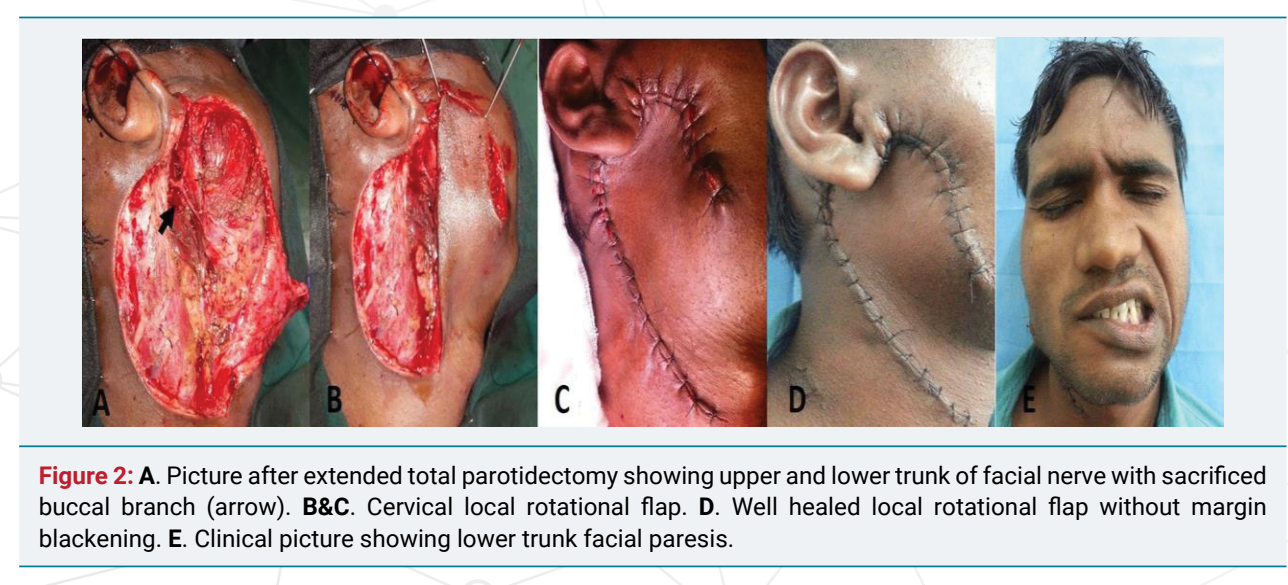




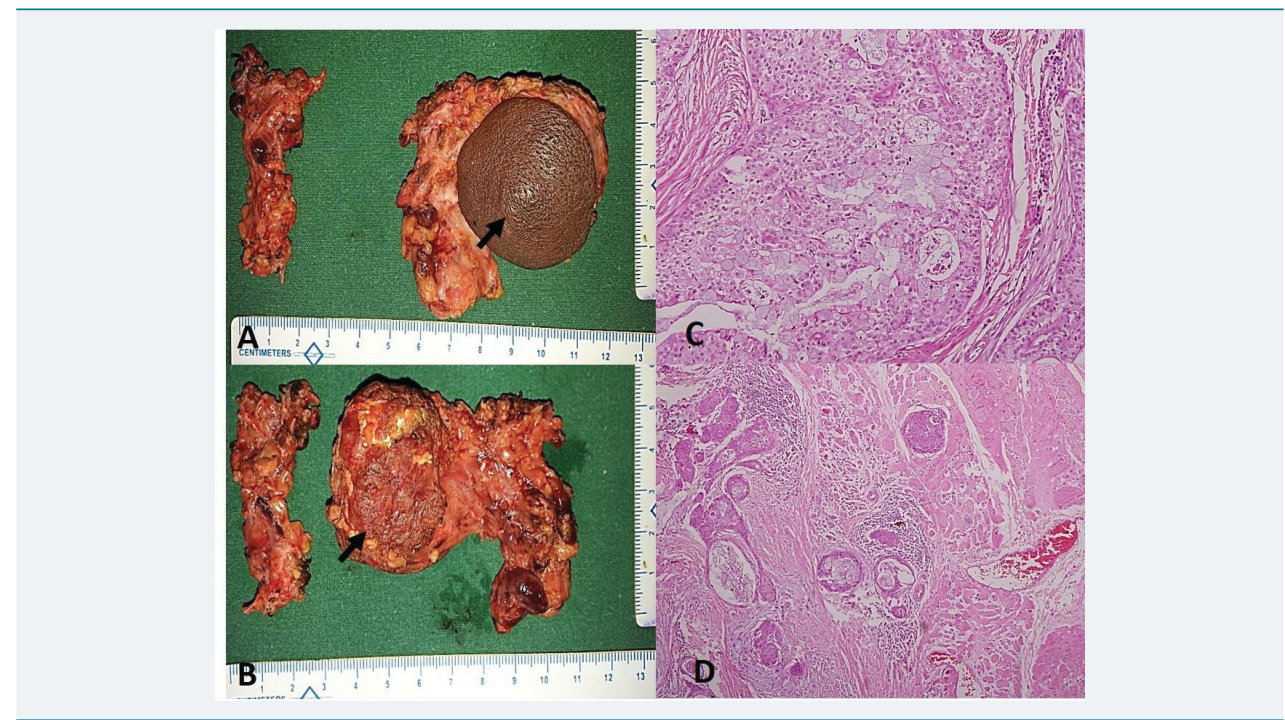

Figure 3: A\&B. Surgical post-operative specimen with skin and masseter involvement (arrows). C. Photomicrograph showing mucous cells and intermediate cells. (H\&E x 200) D. Tumor cell nests infiltrating into the adjacent skeletal muscle. (H\&E x 40).

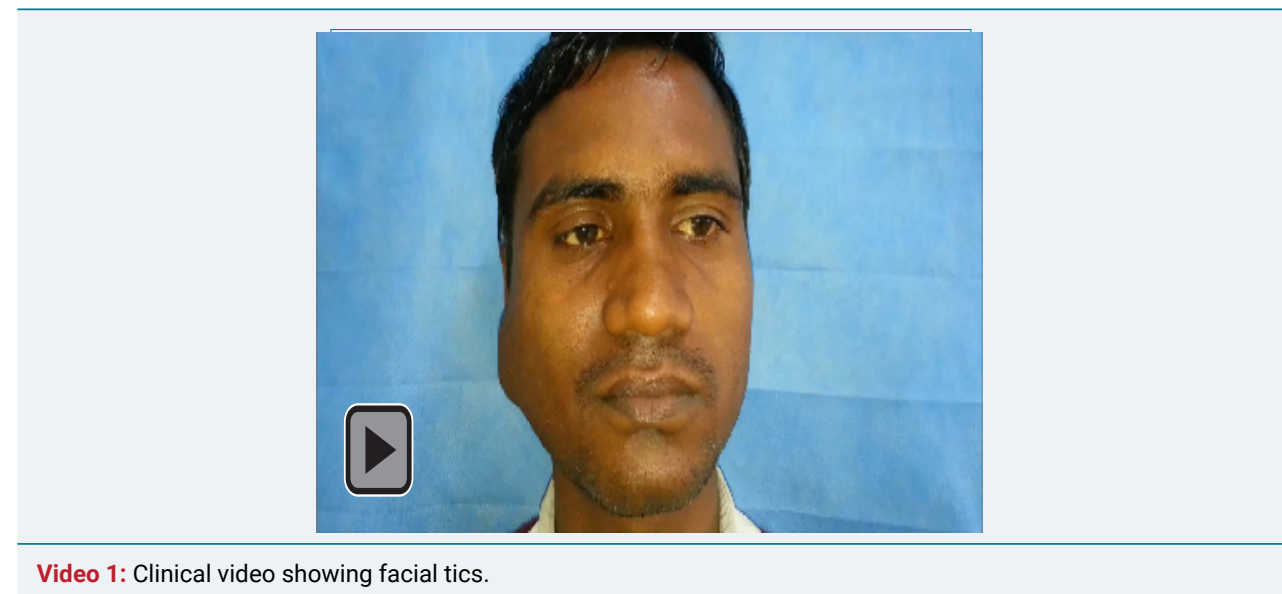

Several molecular markers have both diagnostic and prognostic value in MEC. MUC1 is associated with a high histologic grade, high rate of recurrence, metastasis, and short disease-free interval [5]. MUC4, on the other hand, is expressed in low-grade MEC and is associated with a low recurrence rate and a long disease-free interval. In addition, the $\mathrm{t}(11 ; 19)$ chromosomal translocation seems to be specific to MEC and predicts a better prognosis. CRTC1/MAML2 translocation imparts a better prognosis even when found in high-grade MEC tumors. Epidermal growth factor receptor (EGFR) is also expressed in approximately two-thirds of MECs15 and may be associated with higher grade irrespective of MAML2 fusion status [2,6].

MEC of the parotid gland characteristically present as a painless solitary preauricular mass approximately 2 to $3 \mathrm{~cm}$ in diameter at initial discovery. Pain, rapid growth rate, skin involvement, pain, facial tics or weakness, trismus, local soft tissue or bone invasion, and enlarged cervical lymph nodes involvement can be seen with high grade malignant lesions. Pain may be associated with perineural invasion and occurs in up to $40 \%$ of malignant tumors. $25 \%$ of malignant parotid tumors can involve facial nerve indicating a worse disease outcome. Long-standing parotid gland masses may compress the facial nerves and cause demyelination in the nerve, which in turn may cause spasms in the facial muscles [2,7]. Without pain or facial weakness, the usual diagnosis will be of pleomorphic adenoma and this may result in under treatment when one is not guided by pathological findings of frozen-section analysis. 
Imaging is required when there is larger and deeper tumors with limited mobility and/or suspected malignancy. Both computed tomography (CT) and magnetic resonance imaging (MRI) are complementary to each other. CT scans are ideal for neck nodes and bony involvement; whereas MRI is better at assessing parapharyngeal space (PPS) involvement and perineural invasion. In dynamic contrast enhancement MRI, malignant salivary gland tumors typically show rapid enhancement and slow washout of the contrast agent. In diffusion-weighted MRI, the apparent diffusion coefficient of malignant tumors is generally lower than that of benign tumors. Ultrasound though not informative as CT or MRI scans; it is most useful in assisting image-guided needle biopsies. Positron Emission Tomography lacks specificity for malignancy because benign tumors may also have fluorodeoxyglucose (FDG) avidity. PET-CT may be useful in assessing regional and distant metastases in the patient with a biopsy-proven malignancy $[2,8]$.

FNAC with a diagnostic accuracy of $79 \%$ is most useful in distinguishing between primary salivary tumors and non-neoplastic inflammatory or infectious processes, lymphoma, and metastases from other nonsalivary primary sites [9]. Due to high falsenegative rate of immunohistochemical stains, it can't be used as a reliable method for differentiating between benign and malignant tumors [10]. An incisional biopsy should never be performed on an indeterminate FNA because this may place the facial nerve at risk and increase the risk of recurrence. Instead, an ultrasound-guided core needle biopsy is an alternative safe option for tissue sampling and enhanced diagnostic accuracy [11].

Surgery (superficial or total parotidectomy) with negative surgical margins is the mainstay of treatment for malignant salivary gland tumors. Every effort should be made to preserve facial nerve when it is not directly invaded by tumor; however, the surgeon should be prepared to perform a total parotidectomy that may y extend into the temporal bone to allow for a proximal negative margin resection of the facial nerve if involved. Intraoperative frozen section helps define histology and guides surgical execution $[2,12]$.

The optimal extent of a neck dissection in N0 cases is unclear. Supraomohyoid neck dissection addresses the most at-risk nodes in levels II and III. Routine sampling of the level II and III lymph nodes improves staging and helps decide the extent of neck dissection to perform. Alternatively, elective neck radiation may be given; however, the performance of elective neck radiation versus elective neck dissection in management of the N0 neck remains controversial $[2,13]$.

Prognosis is largely based on age, clinical stage, and grade. A lack of consistency amonggrading systems has led to a discrepancy in reports on prognosis for intermediategrade MEC. This discrepancy can be explained by the use of multiple grading systems, including the Armed Forces Institute of Pathology (AFIP) system, Brandwein system, and the Modified-Healy classification [14]. Chen and colleagues found that the Brandwein grading system predicted low-grade behaviour in intermediate-grade MEC [15]; however, Aro and colleagues used the AFIP grading system and suggested intermediate-grade MEC be treated like high-grade tumors $[15,16]$. Overall prognosis of MEC is favourable with a 5-year overall survival of 79\% but depends upon grade [2].

\section{CONSENT}

Informed written consent was obtained from the patient for publication of the images.

\section{REFERENCES}

1. Batsakis JG. Salivary gland neoplasia: an outcome of modified morphogenesis and cytodifferentiation. Oral Surg Oral Med Oral Pathol. 1980; 49: 229-232. Ref.: https://goo.gl/uEHbHO 
2. Lewis AG, Tong T, Maghami E. Diagnosis and management of malignant salivary gland tumors of the parotid gland. Otolaryngol Clin North Am. 2016; 49: 343-380. Ref.: https://goo.gl/ErY1IS

3. Spiro RH, Huvos AG, Berk R, Strong EW. Mucoepidermoid carcinoma of salivary gland origin: a clinicopathologic study of 367 cases. Am J Surg. 1978; 136: 461-468. Ref.: https://goo.gl/daulo8

4. Boahene DK, Olsen KD, Lewis JE, Pinheiro AD, Pankratz VS, et al. Mucoepidermoid carcinoma of the parotid gland: the Mayo clinic experience. Arch Otolaryngol Head Neck Surg. 2004; 130: 849-856. Ref.: https://goo.gl/UsSx3m

5. Bishop JA, Yonescu R, Batista D, Yemelyanova A, Ha PK, et al. Mucoepidermoid carcinoma does not harbor transcriptionally active high risk human papillomavirus even in the absence of the MAML2 translocation. Head Neck Pathol. 2014; 8: 298-302. Ref.: https://goo.gl/KUo7rs

6. Nakano T, Yamamoto H, Hashimoto K, Tamiya S, Shiratsuchi S, et al. HER2 and EGFR gene copy number alterations are predominant in high-grade salivary mucoepidermoid carcinoma irrespective of MAML2 fusion status. Histopathology. 2013; 63: 378-392. Ref.: https://goo.gl/bfjbDn

7. Wierzbicka M, Kopec T, Szyfter W. The presence of facial nerve weakness on diagnosis of a parotid gland malignant process. Eur Arch Otorhinolaryngol. 2012; 269: 1177-1182. Ref.: https://goo.gl/mX9VrF

8. Razfar A, Heron DE, Branstetter BF 4th, Seethala RR, Ferris RL. Positron emission tomographycomputed tomography adds to the management of salivary gland malignancies. Laryngoscope. 2010; 120: 734-738. Ref.: https://goo.gl/2zCsfy

9. Vander Poorten V, Bradley PJ, Takes RP, Rinaldo A, Woolgar JA, et al. Diagnosis and management of parotid carcinoma with a special focus on recent advances in molecular biology. Head Neck. 2012; 34: 429-440. Ref.: https://goo.gl/uYMp7i

10. Schmidt RL, Hall BJ, Layfield LJ. A systematic review and meta-analysis of the diagnostic accuracy of ultrasound-guided core needle biopsy for salivary gland lesions. Am J Clin Pathol. 2011; 136: 516 526. Ref.: https://goo.gl/LKluvn

11. Pfeiffer J, Ridder GJ. Diagnostic value of ultrasound-guided core needle biopsy in patients with salivary gland masses. Int J Oral Maxillofac Surg. 2012; 41: 437-443. Ref.: https://goo.gl/TaiJVj

12. Olsen KD, Moore EJ, Lewis JE. Frozen section pathology for decision making in parotid surgery JAMA Otolaryngol Head Neck Surg. 2013; 139: 1275-1278. Ref.: https://goo.gl/q8II2U

13. Ettl T, Gosau M, Brockhoff G, Schwarz-Furlan S, Agaimy A, et al. Predictors of cervical lymph node metastasis in salivary gland cancer. Head Neck. 2014; 36: 517-523. Ref.: https://goo.gl/3HK2X9

14. Seethala RR. An update on grading of salivary gland carcinomas. Head Neck Pathol. 2009; 3: 69-77. Ref.: https://goo.gl/y6Pdb9

15. Chen MM, Roman SA, Sosa JA, Judson BL. Histologic grade as prognostic indicator for mucoepidermoid carcinoma: a population-level analysis of 2400 patients. Head Neck. 2014; 36: 158163. Ref.: https://goo.gl/Lalect

16. Aro K, Leivo I, Makitie AA. Management and outcome of patients with mucoepidermoid carcinoma of major salivary gland origin: a single institution's 30-year experience. Laryngoscope. 2008; 118: 258-262. Ref.: https://goo.gl/slORsW 